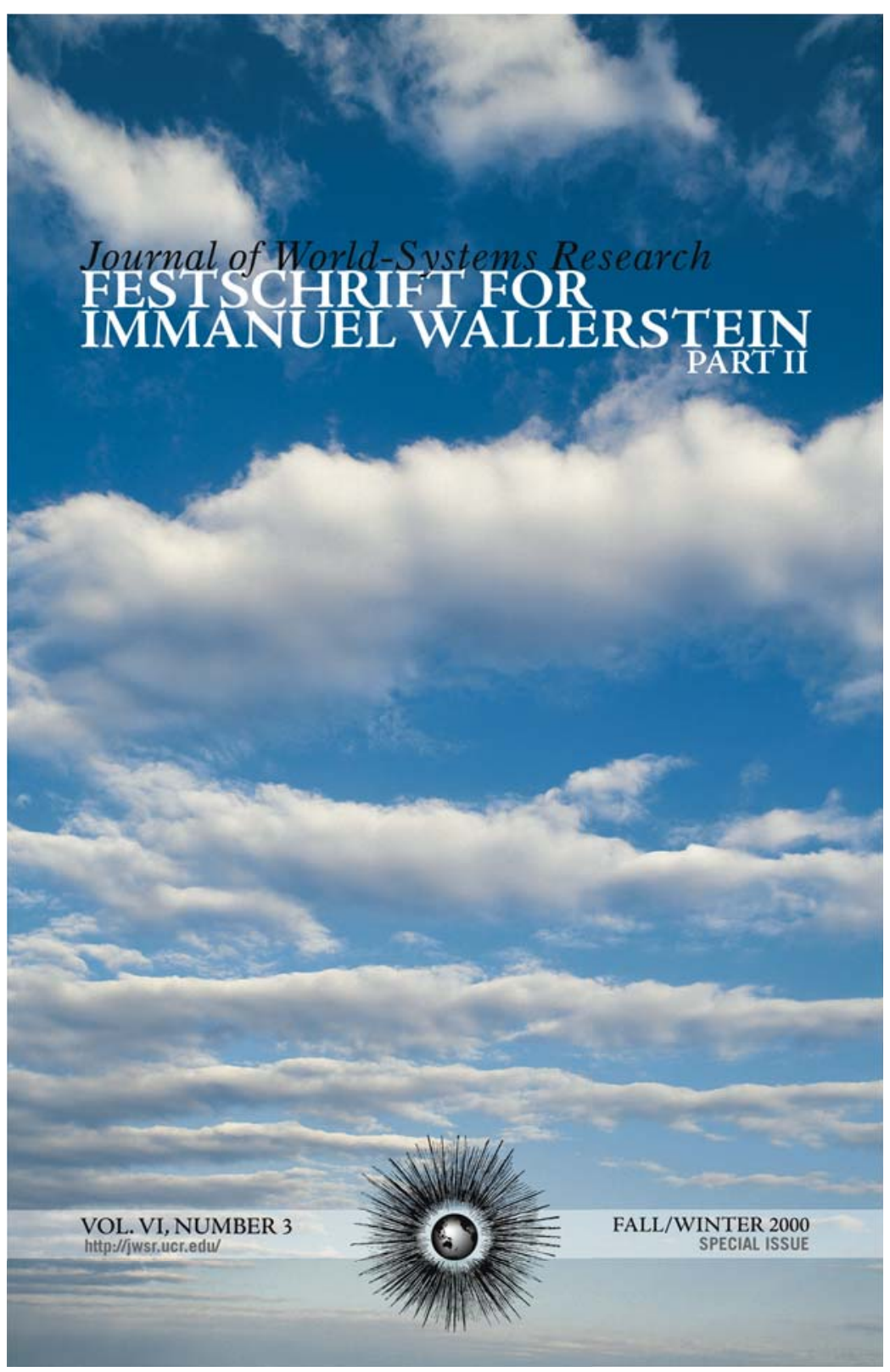

\title{
The Civilizational Orientation in the Making of the New World
}

Anouar Abdel-Malek

To the living memory of Joseph Needham, maitre en l'art de civilisation

Great intelligence embraces,

Small intelligence discriminates.

Great talk is sparkling,

Small talk is verbose.

-Tchuang-Tseu

(1) The historical moment of the position of the problem, from the onset, leads to the heart of the sudden perplexity about the nature, rôle and prospect of "the civilizational question" in our times.

While the very category of "civilization" was avoided until recently, a flurry of amazement-cum-disquiet has been pervading the public mind, more specifically the intellectual circles used to the long-prevailing dichotomies of social thought ("left" and "right"; "developed" and "under-developed"; "center" and "periphery"; "conservative" and "radical"; "reactionary" and "progressive"; "religious" and "secular").

All of a sudden, as it were, on the morrow of the implosion of the former U.S.S.R., the end of the bi-polar system, the advent of unipolar world hegemonism in 1989-1991, a resounding essay in 1993 came as a shock. "Civilizations," finally in the limelight, were deemed to "clash."

(2) History indicates that "civilizations" were recognized as distinct constellations of socio-cultural formations since early times - much before "the making of international society" as we came to know of it, from the end of the $15^{\text {th }}$ century to our time. 
(2.1) Ancient history is made of the parallel existence of such major constellations, mainly the civilizational empires of Egypt, Persia, China in the heartland, while the Western hemisphere witnessed the Aztec, Maya and Incas, to mention but the major recognized macro-formations.

(2.2) At a much later date, socio-cultural formations in Europe were united under Rome, till the beginnings of its weakening in what became known as the dark Middle Age (of Europe). Simultaneously, four major constellations could be recognized, outside the limited European-Roman sphere:

(a) China, maintaining its continuity since its formation, twentyfive centuries B.C. to this day.

(b) The central area of Islam, in South-West Asia and North Africa, around the Arab caliphates and shi'âh Iran.

(c) The Indian sub-continent with a predominant Hindu culture while power was mainly the domain of Muslim rulers.

(d) The Mongol Asian and Eurasian world, which came under Muslim rule during recent times.

In Europe proper, Rome was gradually succeeded by the rise of catholic Christendom, albeit at a much slower pace than the four circles of the Orient.

These constellations, recognized as so many "civilizations" by latter day historians, remained unconnected, except for short periods, or by chance, till the Silk Road provided the major instrument for intercivilizational, mainly commercial, exchanges.

From the $11^{\text {th }}$ century onwards, the rising power of Europe unleashed its protracted warfare against Islam in the Arab world (" $b$ " above). The Crusades were launched under a purported religious-civilizational banner, while being, in essence, a classical sequence of military waves of plunder and subjugation-directly leading to the concentration of "historical surplus value" in the hands of the rising bourgeoisies.

These centuries led to the successive waves of colonialism, clas- sical imperialism and hegemonic imperialism, from the $17^{\text {th }}$ century to our times. Hence, these economic-military-political processes, accompanied by the spread of cultural hegemonism, were described as instances of "civilizational" wars. This also leads to the emergence of the ethos of "clash" side by side with the categories of "cultures" and "civilizations" in recent times.

(3) Yet, the question remains: why now? why this sudden acuity, amidst gloom verging on despair, in the world of plenty?

(a) The cultural-civilizational factor has always accompanied times of tension, change and transformation: the decline of Pharaonic Egypt, facing the northern invasions; of the Roman empire, at the time of the Christian challenge; of Islam after the demise of the rising power of Europe; the waning of Indian cultures in Central, South then North America crushed by Western invasions; the crises of the Ottoman and Mongol empires. The more recent feature of the Western world as of the October 1917 revolution, when the battle raged between Slavophiles and Westernizerstill the 1991 implosion of the USSR. China remained immune to confrontations until the $19^{\text {th }}$ century, accompanied by Japan, while Southeast and South Asia clashed with Western invasions some two centuries earlier.

(b) This factor was recognized as the struggle for maintenance against intrusions-the definition of actors as "nations," "cultures," "civilizations" being the latter day descriptive terminology of history at the center of the human and social sciences.

Maintenance thus became synonymous with normality. The normality of a world defined by the centrality of the West, mainly Europe then, more recently, North America, is surrounded by the "other," fringes of societal formations marginalized by realconcrete history to the periphery. The "other," past civilizational empires and geo-cultural areas, as well as the continuity of distant China, is seen as antique, exotic regions where strange processes unfolded, and as the realm of exceptionalism.

In a word: normality was synonymous with the maintenance of the centrality, or hegemony, of the West-from the end of the $15^{\text {th }}$ 
century till mid- $20^{\text {th }}$ century.

To the central interrogation: "Why now?" the answer must be sought in the realm of world transformation, in the changes of the West enjoying prevalent centrality and hegemony since the $15^{\text {th }}$ century.

(4) At this juncture, it seems relevant to consider the impact of five centuries of Western centrality and hegemony on the movement of ideas, as well as Weltanschauungen (visions of the world), the general mold of the human and social sciences.

(a) From its very beginning in the $18^{\text {th }}$ century, international societyi.e., Europe at the center of the constellation of dependent countries, cultures, nations, social formations-viewed the whole as one entity: the "universality" of the constellation-excluding, at that time, most of the Asian continent-led to the emergence of "universalism." Hence the definition of this ensemble as the all-encompassing "civilization," bringing together all component parts and factors-what obtained in the center being deemed "normal," representing "universal" modes of being and values, to be accepted by the peripheries. From the onset, this postulated one and unique "civilization" was seen as the eternal mold and norm of human societies, past, present and future. Alterity was not accepted, except as the "other" to be negated or normalized via reductionism. Monstesquieu's "Comment peut-on être Persan?" candidly expressed this vision, forgetting that Persia, Egypt, China antedated the new limited world of the European bourgeoisies by tens of centuries.

(b) This overall vision of the world pervaded the very structuration of the tools of investigation and interpretation of human societies. What obtained was deemed to be normal. The central group of societal formations was seen as being able to provide the raw materials, as it were, for interpreting the whole range of societies in terms of universality: the sectoral character of the whole network of concepts and notions was ignored, in the sure thought that the purported universality of the world as it obtained for five centuries could serve as the valid basis for asserting the uni- versal character of emerging theories. The sectoral, European, then Western-centered, nature of the whole range of valuable knowledge about human societies was deemed to interpret the whole, to be "universally" valid as many concepts, laws, the substance, the theoretical work led to the elaboration of distinct fields and approaches that become universally valid human and social sciences.

The "rest" of the world could only be understood in terms of this set of ideas. Thus, if the concept, say, of "nation" was deemed to be a recent rendering of processes of societal coalescence in major European societies, it followed that there could be no nations prior to the beginnings of European modern times, let alone in human societies of the peripheries. Reductionism thus became the core-philosophy of human and social sciences: what was good for the center could not fail to be good for the peripheries.

(5) Then, as of the early $19^{\text {th }}$ century, the earth trembled. The negation of the "other(s)" via the iron claws of reductionism led to the rise of the hitherto negated societies, deemed dormant, or not able to take action. Already, the first tremors during the $16^{\text {th }}$ to $18^{\text {th }}$ centuries, had signaled that deep layers were on the move, beneath the serene patterns of Western hegemony as universalism.

(a) The response of the hitherto marginalized societies (the "peripheries," the Three Continents of Asia, Africa, Latin America), while directly motivated by the ruthless economic exploitation of imperialism, took the path, and adopted the categories and terminology, of the "nation": national movement, party; national liberation movement or war; national sovereignty, independence; united national front ranging to national renaissance.

The liberation of oppressed societies, viewed in this national context and ethos, implied the cultural dimension, often seen as the national-cultural heartland of mounting historical waves of liberation and reassertion of oppressed societies, within a wider, perceived mold of more ancient origins - religions, continents and civilizations. The last term is used as a descriptive tool rather than in essentialist terms. It is used only when continuity, maintenance 
through time, was perceived to a meaningful degree, the living tradition of "the present as history."

(b) On "the other side of the river," the rising challenges had to be identified. Thus came the notion of "the Orient." This notion found ever widening resonance in the domains of the philosophy of history, romantic poetry, exploration and travel literature, echoed in political and diplomatic documents. Differences were deemed to belong to the very essence of dependent, subjugated societies, but rarely accepted as the result of historical dialectics, of real-concrete political, economic, cultural-spiritual struggles between real-concrete forces through recent times.

As of the $11^{\text {th }}$ century, and more so, since the $17^{\text {th }}$ century, the "other(s)," the "savages," "primitives" or "infidèles" were gradually fused into "the Orient," which was seen as mysterious, abnormal, dangerous - at best "exotic" for lighter minds. In each and every case, in all instances, it constituted the world of exceptionalism.

Hence came the general tonality of "Orientalism," which gradually became a field of studies, more so of cultural imperialism. It led to the imperative of firmly keeping the sciences of man and societies, as well as social thought, immune to the formative processes at work in "the Orient," so as to preserve their integrity as the one and only body of normality, of accepted knowledge. Hence reductionism as method.

Reductionism is the intellectual expression of hegemonism. It pervades the very texture of dominant cultures, and prepares the minds and feelings for an adversary, hostile attitude towards the temporarily weaker societies.

(c) Real concrete struggles and creativity changed the world from Mohammed Ali's surge in Egypt (1805), via the Meiji Ishin in Japan (1868), to the liberation of China after the Long March (1949), followed by Vietnam (1973). In less than 150 years, the "Orient," in fact the whole range of societies in the Three Continents, achieved independence and sovereignty, albeit on vastly different terms. While large sectors of the formally independent countries are compelled to be marginalized, other major sectors are going through momentous processes of development, mainly so in East Asia with corresponding degrees of political impact on processes of world transformation.

(6) World transformation, around the momentous 1949-1973 period, was and remains perceived from several simultaneous approaches.

(a) The gradual displacement of the center of gravity of economic growth from the Atlantic to the Asia-Pacific area, centered around East Asia, a process all the more disconcerting as advanced technologies remain mostly in leading Western centers.

(b) Although tempered by "social capitalism," notably in Germany, France and most Western European counties, the cynical triumphalism of the shareholder, as against the stakeholder, transnational financial hegemony gave rise to mounting unemployment, frustration, erosion of belief and value systems. "Crisis" became the pervading feeling in advanced industrial societies of the Western world. In East Asia, principally the historically unparalleled economic growth of Japan, and now, more strikingly so, China, hand in hand with the circle of "Asian tigers" and NICs in East and Southeast Asia, and the Pacific façade in all parts of the American hemisphere, showed that Asian societies are able to cope with the inevitable contradictions of social dialectics, thanks to deeper, non-economic, formative factors. The group-centered, communitarian approach, social cohesiveness and consensus, the resilience of family, nation, state, cultural specificities, accompanied by the inevitable "aggiornamenti" marks a historical epoch of the rise of the major centers of the Orient.

(c) Thus, the stage is reached for maximal contradiction at the world level: while strategic power and advanced technologies still remain in the hegemonic Western world, the major interrogations and alternative models for human and social development are being presented by the Orient - in its widest circles — centering around the East Asian hinterland.

"Historical initiative," clearly changing course, is seen by leading circles of the Western world as a direct challenge to its future course. And this challenge is more often than not perceived in 
circles wider than the economic-military-political matrix. Hence the re-emergence of "culture" and "civilization," religion and visions of the world.

Processes of world transformation are perceived as world crisis, the crisis of the West leading to its decline.

Thus, the stage is set for confrontation, as the inevitable line of defense.

Of whom? Against whom?

(7) At this stage, the introduction of the difference between "units of analysis" and "units of analysis and action" helps clarify the field.

(7.1) "Units of analysis," in the domain of macro-societal formationsbeyond the tribe, ethnic group, social class_-can be seen to comprise four main components:

(a) "Nations" as the optimal mold ensuring the continued coexistence of recognizable cohesive, stable demographic concentrations.

(b) "Nation," in the broadly accepted definition of modern social sciences, around its center of social power, the State.

(c) "Geocultural area," bringing together a group of nations, usually via the media of one, or a limited number, of language(s) as unifying instrument(s) of culture. Usually, though not always, such groups of nations are located in distinct proximate geographical space.

(d) "Civilizations" (or civilizational molds, or circles): the wider circle, as a post-fact description of the major circles which coexisted, mainly without organic links and interaction, until the making of international society as from the $15^{\text {th }}$ century. These circles were distinguished, came to be recognized by a specific network of beliefs, visions of time and the world. They sometimes revolve around different structurations of key concepts, which are the net result of the "depth of the historical field."

(7.2) "Units of analysis and action" attempt to identify the major actors and the subjects of historical dialectics.

This is the domain of "nations": they, alone, enjoy the "depth of the historical field" which renders feasible the optimal actualization of potentials, thus giving voice to the hidden part of the iceberg. It is a matter of decisive importance for meaningful action.

Nation is the major variable, around its national state. State can also be obtained in non-national societal formations, but in a much weaker mode, of secondary or marginal efficacy.

And yet, major confrontations in history invoked wider frames of reference: religion, during the Crusades, as well as during the Iberian conquests of Central and South America; civilization during the heyday of colonialism and imperialism, the "civilizational mission of Europe" facing the barbarians; as well as the more recent "new international order" proclaimed by the uni-polar hegemonic center, where the normative approach ("order") acts as the ideology of hegemonism.

To be sure, major identification labels were and still are chosen to cover action programs in such terms, which help to mobilize the deeper layers of identity and cumulative achievements. The "Asian peril," followed by the dangers of "Islamic fundamentalism," is in lieu and place of the shifting pattern of historical initiative, and the control of the world's oil resources menaced by radical nationalism.

Yet, when all is said and done, civilizations and cultures do not launch wars, nor conclude peace. The nations of the world, around their respective states, are the major recognizable actors, bringing together the two circles of social dialectics: the inner (ethnic, social class); and the outer (international, world politics).

Nations, yet, are always influenced by outer molds of their respective cultures and civilizations.

(8) How could the mounting tensions of the times of world transformation develop? Is there a space for meaningful action in a domain where the winds of change are blowing, impetuously, more than at any previous time in the history of mankind?

Tensions lead to confrontations, that is, the clash approach in international relations. A glance at the panoply put forth by the epigones of this approach, which claims the non-strategic-political character of the 
new conflicts after the end of the Cold War, reveals the intention to maximize tensions and contradictions to the level of direct confrontation.

(a) The first range of problems is of the classical economic-cumpolitical sort, yet in novel terms. Water, instead of oil, reserves; ecology that sets the limits to the menacing growth of the peripheries; new technologies, mainly in the field of informatics; the spread of new dangerous diseases, often leading to mass epidemics, side by side with the resurgence of old pathologies deemed extinct, and the growing inefficacy of existing therapies; the spread of hard drugs; the mounting menace of massive migrations towards the industrial societies, etc.

Little, if anything, is put forth to search for meaningful solutions and limit the damage. In fact, the above listing comes as there are many menaces in addition to the panoply of traditional strategicmilitary and economic conflicts, such as the persistent nuclear menace.

(b) "Human rights" occupy the center stage. This is, precisely, where the theses of the center-projecting itself to encompass the world, via the successive waves of reductionism-can only but differ from, and collide with, the visions of other civilizations, cultures and national specificities. The tacit acceptance of the centrality of the individual in Western societies, as of the development of the European bourgeoisies owing to the range of possibilities offered by cumulative "historical surplus value," leads theoreticians and policy makers of the hitherto prevailing central area to refuse the legitimacy of the parallel set of processes unfolding in Oriental societies in their different geocultural areas, which give primacy to the group, community and togetherness. They are placed before the individuation of social life.

A non-confrontational approach would stress the rights of peoples side by side with the rights of man. The confrontation approach chooses to denounce Oriental "despotism," seldom recognizing the visions and life patterns of the "other(s)." A stage has been reached where human rights are invoked to justify mili- tary intervention, economic blockade against nation states, popular movements and schools of thought which choose to keep their own course.

(c) Democracy, rather "liberal market democracy," is deemed to be the socio-political and ethical norm for all societies. The crisis of socialist state formations in Europe leads to the negation of the very possibility of socialism, let alone its powerful assertion in a large part of the world.

(d) In the name of the above, military-political institutional alliances are brought to ever more advanced levels of strategic power. N.A.T.O. is now extending towards the frontiers of Russia, towards Asia, via the oil reserve area in Central Asia.

In the name of "civilization," the one and only one.

(9) It is our opinion that another path can be charted: the non-antagonistic treatment of contradictions, leading to complementarity.

(9.1) "Contradiction" is of the essence. The European (Western) concept, from Aristotle to Hegel and Marx, of contradiction has been conceived in antagonistic terms: thesis facing antithesis leading to the supersession of both sides in the resulting synthesis. From the onset, conflict and warfare are postulated as the path to deal with contradiction. This vision has enabled the West to open, conquer, discover and innovate. It has also led to the resolution of contradictions by the launching of the atomic bombs in 1945, and genetic manipulations in our times.

The Chinese philosophical tradition, from Taoism to Mao Tsetung thought, puts forth that "contradiction is the essence of being." As such, it cannot be "overcome," eliminated via the removal of one side, and/or its forcible taming by the other. Real-concrete life, in nature and human societies alike, shows the persistent structuration of reality in terms of contradiction. While remodeling the pattern of the interrelations between different component elements of the contradiction, the readjustment of their respective role and impact opens the path for the combination between continuity and change, maintenance and transformation. This is the hallmark of the rising Orient in Asia in our times. 
(9.2) Since the early European Middle Ages, facing the difficulties of propagating the Christian faith in the Islamic-Arab world, Central and South America, later Africa and Asia, the Jesuits proposed the concept of "inculturation": the message of the new, Christian faith could only be understood if it followed the specific nature of other cultures, faiths and peoples.

This major step in European thought remains inadequately understood, and its efficacy from Ricci's mission to Ming China in the $16^{\text {th }}$ century to "liberation theology" in our times remains marginalized.

(9.3) One more step was needed to further develop the call for recognizing identities. Such was the purpose of our work to develop the concept of "specificity" (1962-70) as the key tool to understand differences, thus helping the bridge-building efforts towards convergence.

The analysis of the concept of specificity can be attempted at three levels/moments:

1. The level/moment of general definition, from the origins. In order to reach for the specificity of a given society, one should seek what has been the pattern of societal maintenance obtained in a given socio-economic national formation through a critical study of its historical development. The particular pattern of this societal maintenance is simply the pattern of structuration of and interaction between the four key factors in every form of societal maintenance: the production of material life in the geographic and ecological framework (the mode of production stricto sensu); the reproduction of life (sexuality); social order (power and the state); the relation to the time-dimension (the limitedness of human life, religions and philosophies). In that group, the production of material life occupies the decisive place in the structuration of the whole pattern of maintenance, but only in the last instance. By applying this model to different societies, we would be in a better position to clarify the general picture, to qualify and to give colour, adding tone and nuance to the first analysis undertaken on the basis of socio-economic criteria.
2. The level/moment of the emergence of spatio-temporal factors to conscious awareness. The study of specificity is not undertaken in the outer world of pure epistemology-but within the framework of the concrete evolution of given societies. This evolution puts the time factor in the forefront; hence the central importance of the notion of the depth of historical field.' There is no specificity in a temporary society-a jamboree, student movement, a state artificially established for show purposes. To talk of societal maintenance is to address oneself to the long historical duration that molds events - not to contingency. So one can validly speak of specificity in the old social-national formations-the ideal terrain for specificity-and in those formations which have not yet reached the level of national evolution stricto sensu-in the new nations,' to use the term coined by Thomas Jefferson in speaking of the United States of America. One can thus see how vast the field is - the immense majority of nations and peoples in our times. The social sciences will feel less at ease with the 'space' factor-because one form of geo-politics has fallen out of favour. However, the historical evolution of societies does not take place in the abstract space of the dialectics of the mind- 'History' in place of 'history' - nor does it unfold in the secluded field of epistemology.

Societies-but only within the framework of their geographical conditions, should be considered under two aspects: (i) the aspect of location, which enables one to assess the importance of location to each society and its state as compared with others, that is, geo-politics; (ii) the aspect of internal conditioning, that is, ecology, which indicates and quantifies resources and potentials, which then had to be tempered by taking the demographic factor into consideration.

3. The moment-dimension of the dialectics of the factors of maintenance and the factors of transformation, on the basis of the ultimately decisive action of the mode of production and in extreme cases of the progress of techniques of production. It is to disentangle the factors which maintained from those which maintain (which is very different from speaking of 'invariables'-of much 
later origin), to distinguish each according to their pattern from that which was not, but is becoming, and that which is, but shall be no more. To distinguish the four linking factors, whatever their relative weight at any given stage of historical evolution.

The concept of specificity will apply to both the hegemonic and the dependent areas, where several factors can be isolated that merit consideration, as they constitute the structuring framework of specificity at the nodal point of meaningful social theory. These problems can be divided into two groups: (i) the uses of the concept of specificity, that is its relevance in different types of society; (ii) the definition of priority areas for comparativism, using the concept of specificity as the main conceptual tool."

(10) Is it now possible to chart the path from "confrontation" and "clash" towards "complementarity" - let alone "convergence"?

(a) Major conflicts in our time and the foreseeable future are, essentially, political-economic in the wider sense. The changing emerging patterns, centering in the displacement of historical initiative, are leading to the crisis of modern hegemony, located in Europe and then North America (the "West"), as the crisis of the "civilizational project" of the West itself. The Promethean-Faustian vision of "man as demiurge," master, let alone creator, of the world, leading to protracted, boundless productivism, consumerism, hedonism. They lead to mounting confrontations and a rising tide of unsustainable scenarios in a finite world, which is the home of a many-splendored panoply of nations, cultures and civilizations.

The crisis of the power system is seen as the crisis of (Western) civilization.

(b) Hence, there is the advent (some would say resurgence) of the cultural-civilizational dimension as the wider frame within which power struggles are unfolding (e.g., the call for a "new Chinese spiritual civilization.").

This realistic recognition of the emerging patterns is brought to its maximal systematic acuity by Huntington's 1996 presentation as of his 1993 theses, thus: "Western belief in the universality of Western culture suffers from three problems: it is false; it is immoral; and it is dangerous.... Imperialism is the necessary logical consequence of universalism.... It could lead to a major intercivilizational war."

(c) To avoid major confrontations, it is of importance to avoid imposing the center's vision, let alone will, upon other cultures and civilizations.

More specifically, we should avoid the theoretical and essentialist approach, while simultaneously reaching for areas of convergence. These areas can be seen to obtain in the domain of the exigencies of the very survival of humankind on our planet Earth: hence the primacy of the normative approach, the attempt to locate common problems, parallel preoccupations, joint efforts to seek viable, concrete solutions to real concrete problems and situations. In a word: it is essential to give priority to the real concrete approach to real concrete problems faced by real concrete societies, albeit in vastly different terms.

(d) This approach can best be implemented by the will of the different formative schools of thought and action at work in the different national, cultural and civilizational areas to confront these obligations, thus fulfilling their duty as organic intellectuals-at work in the domains of knowledge-cum-policy formulation and implementation.

Once more, once again, there is a rising role for the socio-cultural factors, as compared to the traditional political-strategiceconomic approach, advocated since 1973 and mainly so, by our concerted joint work at The United Nations University during its seminal formative stage (1975-1985). An approach now echoed by Huntington ("Peoples of all civilizations should search for and expand the values, institutions and practices they have in common with peoples of other civilizations.")

(e) If all subjects/factors of history are invited to take their full part in these processes towards survival, complementarity leading to convergence, the two cultural-civilizational circles comprising the higher density of the oldest societies and nations-the Orient, and Europe; both in their wider connotations - can be seen to be 
called upon to take joint action, based upon their exceptionally rich experience in the changing patterns and fortunes of historical dialectics.

"Civilizational strategy" should welcome different scenarios and initiatives, different levels and tempi.

Our contention, throughout, has been and remains that differences, if recognized, can open the path towards convergence.

Our plea throughout, has been and remains that it is now imperative and urgent to take meaningful action.

Our hope, our decision, throughout, have been and must firmly remain to trust that the combined lucidity and realism of our humankind will prevail over the negative mind and nihilism. Confrontation and clash, if understood, can open the path towards complementarity, convergence-our joint, richer, futures.

The civilizational dimension and approach facilitate the transition from the crises of world transformation towards the challenges and promise of the making of a new world. 